\title{
Alcohol Badly Affects Eye Movements Linked to Steering, Providing for Automatic in-Car Detection of Drink Driving
}

\author{
Dilwyn E Marple-Horvat*,1,2, Hannah L Cooper ${ }^{1,2}$, Steven L Gilbey ${ }^{2}$, Jessica C Watson ${ }^{2}$, Neena Mehta ${ }^{2}$, \\ Daljit Kaur-Mann ${ }^{1,2}$, Mark Wilson' and Damian Keil' \\ 'Institute for Biophysical and Clinical Research into Human Movement (IRM), Manchester Metropolitan University, Cheshire, UK; ${ }^{2}$ Department \\ of Physiology, School of Medical Sciences, University of Bristol, University Walk, Bristol, UK
}

\begin{abstract}
Driving is a classic example of visually guided behavior in which the eyes move before some other action. When approaching a bend in the road, a driver looks across to the inside of the curve before turning the steering wheel. Eye and steering movements are tightly linked, with the eyes leading, which allows the parts of the brain that move the eyes to assist the parts of the brain that control the hands on the wheel. We show here that this optimal relationship deteriorates with levels of breath alcohol well within the current UK legal limit for driving. The eyes move later, and coordination reduces. These changes lead to bad performance and can be detected by an automated in-car system, which warns the driver is no longer fit to drive.

Neuropsychopharmacology (2008) 33, 849-858; doi: I0.1038/sj.npp. I 30 I458; published online 16 May 2007
\end{abstract}

Keywords: alcohol; eye movements; steering; coordination; impaired; driving

\section{INTRODUCTION}

In diverse everyday activities (Land and Furneaux, 1997; Land and Hayhoe, 2001), including walking (Hollands et al, 1995; Hollands and Marple-Horvat, 2001), reaching to an object (Herman et al, 1981), playing a musical instrument (Sloboda, 1974; Furneaux and Land, 1999) or ball games (Land and Furneaux, 1997), eye movements precede other actions. Driving is a classic example, in which eye movements anticipate motion of the steering wheel when negotiating a winding road. This relationship is so strong that it is convincing to the naked eye in the raw records obtained by Land and Lee (1994) showing left-right eye movements as subjects drove around left and right hand bends of a typical suburban route.

The importance of such eye movements ahead of and linked to other actions is betrayed by the effect on performance when the usual coordination is disrupted. Cerebellar patients who are unable to move their eyes appropriately in relation to their actions, making eye movements of the wrong size or at the wrong time, perform badly in visually guided tasks (van Donkelaar and Lee, 1994; Crowdy et al, 2000; Marple-Horvat and Crowdy, 2005). They improve their performance if they first improve their eye

\footnotetext{
*Correspondence: Dr DE Marple-Horvat, Institute for Biophysical and Clinical Research into Human Movement (IRM), Manchester Metropolitan University, Hassall Road, Alsager, Cheshire ST7 2HL, UK, Tel: + 44 I6I 247 5535, Fax: + 44 |6| 2476375 ,

E-mail: D.E.Marple-Horvat@mmu.ac.uk

Received 20 April 2006; revised 3 April 2007; accepted 16 April 2007
}

movements (Crowdy et al, 2002). Healthy individuals also experience difficulty when they are instructed not to move their eyes, so destroying the usual coordination. Several aspects of driving performance are impaired, such as positioning in-lane, and completion time when racing (Wilkie and Wann, 2003; Marple-Horvat et al, 2005). When driving under critically reduced visibility of the road ahead, drivers who nevertheless persist in moving their eyes so as to maintain their usual eye-steering coordination suffer a smaller performance deficit than those who allow that coordination to degrade (Wilson et al, 2007). All of this suggests that optimal coordination between eye movements and other actions is required for best performance of those actions.

This optimal coordination sheds light on the way in which the brain solves problems involving coordinated movements under visual guidance in general. A strategy in which the eyes move with a time (or phase) lead over other body movements provides for the oculomotor controller, perhaps by efference copy of its output, to assist the neural centers controlling voluntary limb movements (Hollands and Marple-Horvat, 1996; Miall and Reckess, 2002). Such a beneficial influence is likely established within the cerebellum, which is known to be crucial for motor coordination (Holmes, 1939; Miall et al, 2000, 2001), and hence degrades with cerebellar degeneration (van Donkelaar and Lee, 1994; Crowdy et al, 2000).

Chronic alcoholism leads to cerebellar degeneration (Haubek and Lee, 1979; Torvik and Torp, 1986; Harper, 1998) and the clinical symptoms of ataxia including loss of coordination (Sullivan et al, 2000; Johnson-Greene et al, 
1997). Acute alcohol intoxication temporarily affects cerebellar function (Chu, 1983), producing symptoms that resemble mild or moderate cerebellar ataxia (Diener et al, 1983; Nieschalk et al, 1999), including loss of coordination between eye movements and other visually guided actions (Crowdy and Marple-Horvat, 2004).

A driver is 50 times more likely to be involved in a fatal accident if driving at twice the legal limit of alcohol, and one in seven of all deaths on the road occur when someone is driving when over the legal limit (www.thinkroadsafety. gov.uk/statistics.htm). Many aspects of driving performance are impaired by even modest doses of alcohol. These include lane keeping, manifest as steering instability and crossing the center line (Ramaekers et al, 2000; Weiler et al, 2000); complex psychomotor tasks such as brake reaction time to an unexpected vehicle blocking the lane, and choice reaction time (Perez-Reyes et al, 1988; Liguori et al, 1999; Weiler et al, 2000); ability to divide attention appropriately between competing tasks and in general information processing (Moskowitz et al, 1985; Ogden and Moskowitz, 2004).

Some of these impairments may be due in part to the effect of alcohol on the cerebellum, which has been revealed by functional imaging during simulated driving. Altered cerebellar activity was associated in a dose-dependent way with impaired driving behavior (Calhoun et al, 2004; Carvalho et al, 2006). Altered cerebellar activity probably disrupts the coordination of eye movements with the actions involved in driving, including steering, just as it disrupts coordination of eye movements and steering on foot, or visually guided stepping, to targets (Crowdy and Marple-Horvat, 2004). This disrupted coordination might explain much of the impairment in driving ability, which underlies the accident statistics.

Driving is high-speed locomotion, different from walking (and from visually guided manual tasks without motion through the environment) in several important ways that make it particularly worthy of study as a separate visuomotor control task. First, it is locomotion at much higher speeds than can be achieved unaided. This makes the control problem more demanding for the nervous system; neural processing delays mean that visual feedback control is far from ideal at even moderate speeds (Miall, 1998) so a driver must achieve predictive feedforward control. Secondly, it is locomotion achieved indirectly through use of a 'tool', the car, and controlled by a manipulandum, the steering wheel. This introduces additional layers of control compared to walking or running. Thirdly, the driven path is usually tightly constrained. There is often great freedom to choose the direction of future steps when walking, whereas the path ahead when driving is usually rather tightly limited to a fairly narrow 'lane' defined by clear boundaries, the kerb to one side and a lane marking to the other. These are not only clearly visible boundaries, they are equally clearly acceptable boundaries beyond which injury to self or others would in many circumstances result. This is perhaps the most compelling reason why the task of driving is worthy of study in itself; no other daily, routine behavior carried out in such large numbers causes so much injury and death (for a comprehensive review, see Evans, 2004). Understanding the nature of impaired driving, any circumstance that brings it about, and its detection is therefore crucial.
This study is important because it identifies and characterizes impairment of a fundamental aspect of driving (rather than some additional task, such as a reaction time test). In this instance impairment is due to alcohol, but impairment thus defined is in principle detectable regardless of why it has occurred-for example, because of fatigue, or other pharmacologically active compounds (legal or illegal).

We have identified the effect of increasing alcohol intoxication on the coordination of eye movements and steering, and on ability to steer safely, and hence fitness to drive, in a driving simulator. Our prediction was that any disruption of the normal, optimal coordination would be accompanied by impairment of driving performance. An important issue for future study is whether the impaired coordination identified in the simulator, and the crash incidents observed, are similar to the change in driving performance and crash incidents that occur in actual driving.

\section{METHODS}

\section{Subjects and Task}

Ten subjects took part, five men, five women (mean age 24.8 years, range 20-36 years); all subjects had at least 2 years' of driving experience (ie novice drivers were excluded). A written statement of informed consent was made by each participant. All procedures were in accord with the Helsinki Declaration of 1975. Subjects fasted from food and alcohol for $12 \mathrm{~h}$ before testing. The driving task was taken from the Colin McRae Rally 2 simulation (Codemasters, Leamington Spa, Warwickshire, UK), a driving environment simplified by the absence of other vehicles and pedestrians. The route was essentially a winding road with little time spent traveling along straight portions without an upcoming bend visible (see Figure 1). Such sections comprised less than $10 \%$ of the total drive time. Subjects drove the same route repeatedly, and were instructed to drive as they would in a real car on a one-way road (to facilitate comparison with a previous study by Land and Lee, 1994). The driving simulator incorporated a 42-inch plasma screen, force feedback steering wheel, pedals and rally car seat; the setup also included an eye-tracking device, which monitored the driver's eye movements, and a potentiometer attached to the steering wheel to monitor its rotation. Although there was no head restraint, the car seat and adjustable head rest were close-fitting, and subjects made only few and small head movements, so that eye movements equated to gaze shifts. Gaze was visualized directly in real-time on a monitor screen behind the subject (visible only to the researchers) superimposed as a cross hair on the driver's view through the windscreen. This scene view with superimposed gaze was videotaped for subsequent playback and analysis.

After an initial $45 \mathrm{~min}$ practice period, over which performance parameters stabilized, a control drive was completed and a breathalyzer reading taken to confirm a starting condition of zero breath alcohol concentration (BRAC). Alcohol levels were measured using an Intoximeters Alcosensor III (St Louis, MO), similar to those used by regional police forces, providing BRAC in micrograms 
a

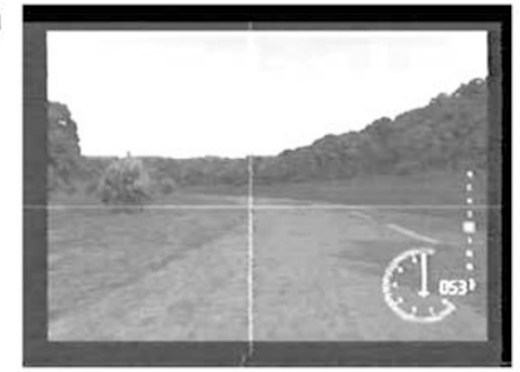

b

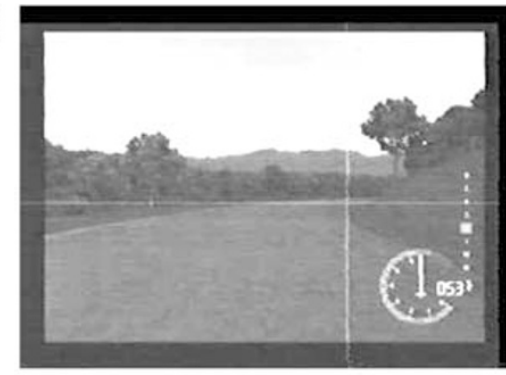

c
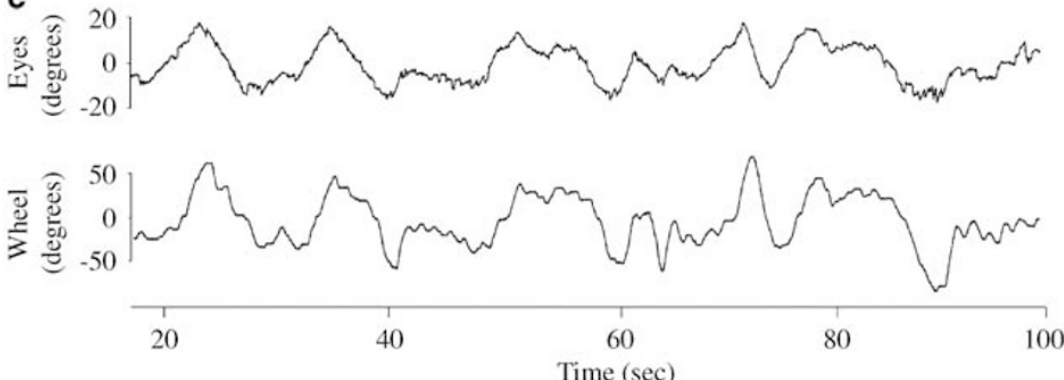

Figure I Video recordings of gaze superimposed on the view of the road, and eye movement and steering signals. (a and b) Video frame grabs during the approach to left and right hand bends in the road, showing the driver's gaze as a superimposed cross-hair fixated on the inside of the curve. (c) Raw data trains reveal that the driver's horizontal eye movements (above) were tightly linked to, and led, their turning of the steering wheel (below).

alcohol per $100 \mathrm{ml}$ expired air. Control measures describing eye-steering coordination were therefore obtained from a drive completed immediately before drinking (at time zero) $40 \mathrm{ml}$ of $45 \%$ vodka (equivalent to about $1.8 \mathrm{U}$ ) mixed with an equal volume of orange juice. After a 10 -min wait to permit absorption of some (although not all) of this first dose into the blood, the subject was breathalyzed, repeated the driving task (first test run), and was breathalyzed again. BRAC during a drive was taken as the mean of the initial and final values. A further $30 \mathrm{ml}$ of vodka (again with an equal amount of orange juice) was administered at time 16 min. After a 6-min wait, the subject was breathalyzed again immediately before a second test run (which therefore began at time $22 \mathrm{~min}$ ), and immediately after completing that second drive. A final $30 \mathrm{ml}$ dose (making $100 \mathrm{ml}$ vodka in total) was given at $28 \mathrm{~min}$, followed by a third test run (beginning at time $34 \mathrm{~min}$ ) again with breathalyzing before and after. This pattern of dosage (alcohol given at time 0,16 and $28 \mathrm{~min}$ ) was therefore determined by two factors, the necessity to allow time for absorption into the blood, and to complete a test drive and obtain BRAC readings before and after. Note that for those subjects tested, BRAC continued to increase beyond the end of the test period.

\section{Data acquisition and analysis}

The eye tracking system was an ASL 504 (Applied Science Laboratories, Bedford, MA) mounted at dash panel height. Analog signals representing horizontal and vertical components of eye movement (calibrated to $1^{\circ}$ accuracy), and steering wheel rotation were digitized at $200 \mathrm{~Hz}$ using a CED 1401 A/D converter (Cambridge Electronic Design, Cambridge, UK) and stored on computer for subsequent analysis.
Cross-correlograms of horizontal eye $v s$ steering wheel movements were generated using a Spike 2 script. Crosscorrelation is a powerful technique for quantitative analysis of eye-steering coordination. Indeed, it is the fundamental time domain analysis used to compare two signals (see Beauchamp (1973); Lynn (1982) for detailed treatments). Specifically, the two signals, one representing the horizontal component of eye movements and the other representing steering wheel rotation, were cross-correlated over the time taken to complete a drive, typically $4-6 \mathrm{~min}$ which, with a sampling rate of $200 \mathrm{~Hz}$, equates to $48000-72000$ data points. The peak of the cross-correlogram identified the correlation coefficient $(r)$, a measure of the covariation of the two signals. A critical value table for $r$ was used to determine whether the correlation ( $r$-value) for each drive was significant. Then $r^{2} \times 100$ (the percent common variance) is the percentage of variance in steering wheel movement that is attributable to, and can be explained by, covariation with horizontal eye movement. These statistics defined the usual degree of coordination between eye movements and steering during the control trial, and the coordination in test trials during progressive alcohol intoxication; a reduction in coordination would indicate that the driver looked less consistently in the impending direction of steering around approaching bends. The time at which the peak of the cross-correlogram was located identified the relative timing between eye movements and steering, or specifically the time lead of eye movements over steering measured across the complete drive.

For each individual driver, $r$ and time-lead values were obtained for the control drive (zero alcohol) and for the three test drives (one after each dose of alcohol). A driver's time-lead values were subjected to regression analysis to identify whether time lead reduced linearly and significantly with increasing BRAC. To investigate any differences 
between individuals in terms of their eye-steering time lead (outcome variable) and BRAC (predictor variable), a multiple regression (or analysis of covariance) was performed by entering subject as categorical predictor variable. This analysis revealed (i) whether any chosen individual was significantly different from some other individuals in the group, and (ii) whether any individuals were significantly different from the group as a whole.

Results from all drivers were brought together to identify any effects of alcohol across the whole group. The control drive was compared with the first test drive (after the first dose of alcohol) and the last test drive (after the full dose). Student's paired samples $t$-test was used to test whether correlation ( $r$ value) and time lead of eye movements over steering were significantly reduced after alcohol intoxication, and specifically while drivers remained below the UK legal BRAC limit for driving.

Time-lead values from all drivers were also subject to linear regression analysis, to obtain a description of the relationship between the two continuous variables (time lead and BRAC) across the whole group data set, and specifically to define the rate of change of time lead with BRAC (gradient of the fitted regression line), clearly an important group measure.

Since the coordination between eye movements and steering when approaching and steering around bends might a priori be expected to depend on the rate of approach, or speed of the vehicle, analysis of group data was performed, including multiple regression analysis, to see whether average speed across the drive could explain any variation in time lead and level of correlation in different drives.

These analyses achieve our main aim of quantifying the relationship between eye movements and steering both for individuals and a group of drivers (see also Marple-Horvat et al, 2005; Wilson et al, 2007). In this study, we have used standard signal analysis techniques and statistical tests to identify whether the usual coordination deteriorated under alcohol intoxication, to quantify any difference, test for significance and determine whether it was accompanied by impaired driving performance. Instances of leaving the carriageway and colliding with an obstacle which stopped the car (major crashes), or glancing impacts after which the car kept going and regained the carriageway (minor crashes), were noted. This allowed for a simple description of impaired driving. Our results overall, therefore, permit insightful assessment of the impact of alcohol on eyesteering coordination and ability to drive safely.

\section{RESULTS}

In every case, drivers' eye movements were clearly linked to their turning of the steering wheel to negotiate bends in the road; as they approached a left-hand bend they looked across to the left (inside) curb some time before turning the wheel to the left, and for a right-hand curve they looked across to the right before turning the wheel to the right. This much was evident from inspection of the gaze cross-hair superimposed on the driver's view as they drove (Figure 1a and b), but was even more obvious in the live data stream from the eye tracker and steering wheel monitor (Figure 1c); the two are very closely matched, with a clearly visible lead of eye movements over steering. This is very reminiscent of the data obtained in a real driving situation (Land and Lee, 1994), indicating that subjects' driving in the simulator when sober was similar to their driving in a real car.

Cross-correlograms representing the overall relationship between a subject's horizontal (left-right) eye movements and turning of the wheel to negotiate bends in the road were computed for each drive. The peak of the cross-correlogram $(y$-value $=$ correlation coefficient, $r)$ identifies the degree and relative timing ( $x$-value) of any covariation or 'linkage' between the two. A critical values table confirmed that all $r$-values, for every drive by every driver, were highly significant $(P<0.001)$.

Figure 2 shows cross-correlograms from one individual, and illustrates the optimal relationship before alcohol (left), which deteriorated progressively with increasing levels of alcohol: below the legal limit (center); well above the legal limit (right). Both the degree of linkage $(r)$ and relative timing of eye and steering movements were badly affected. The correlograms reveal that for this driver, when sober, $76 \%\left(r^{2} \times 100\right)$ of the motion of the steering wheel can be attributed to it varying with (and following) movement of the eyes; after just the first dose of alcohol (equivalent to one and a half vodkas and orange) this has fallen to $63 \%$, and it falls further (to 52\%) with further drinking. The timing of eye movements was even more affected. These led movements of the wheel by almost two-thirds of a second $(0.61 \mathrm{~s})$ before alcohol, but as the subject drank more and more, this time lead reduced more and more because the eyes moved later and later until eventually there was hardly any time lead at all, less than a tenth of a second $(0.098 \mathrm{~s})$. This subject's eyes were then moving just as the car hit the bend, rather than a safe interval before this. The time-lead values obtained from the control drive (zero alcohol) and for the three test drives (one after each dose of alcohol) were subjected to regression analysis which confirmed that time lead reduced linearly and significantly $(r=0.954, P<0.05)$ with increasing BRAC. For this subject, $91 \%\left(r^{2} \times 100\right)$ of the variation in time lead across the control and three test drives is explained by BRAC.

Figure 3 shows that these effects of alcohol on both aspects of coordination, level and timing, were seen to varying degrees across all subjects, and became apparent below the current legal limit for driving, which is a BRAC of $35 \mu \mathrm{g} / 100 \mathrm{ml}$. For seven of the ten drivers, time-lead values reduced progressively with increasing BRAC in a significant linear relationship, $r>0.90, P<0.05$. (The remaining three drivers also showed reduced time lead with increasing BRAC, but with lower $r$-values: $0.88,0.84$, and 0.73 ). The $r^{2}$-values for all 10 drivers are shown in the inset to Figure 3a. Strikingly, this separate regression analysis of each individual's data revealed that for six subjects more than $90 \%$ of the variation in time lead $\left(r^{2} \times 100\right.$, the percent common variance) across control and test drives is explained by BRAC. At the level of an individual driver, for the majority of those tested, BRAC is therefore an extremely powerful predictor of the relative timing between eye movements and steering. Between drivers, however, there was substantial variation in the timing $v s$ BRAC relationship. Thus, the gradients of the individual regression lines ranged from a reduction in time lead of $183 \mathrm{~ms}$ for 

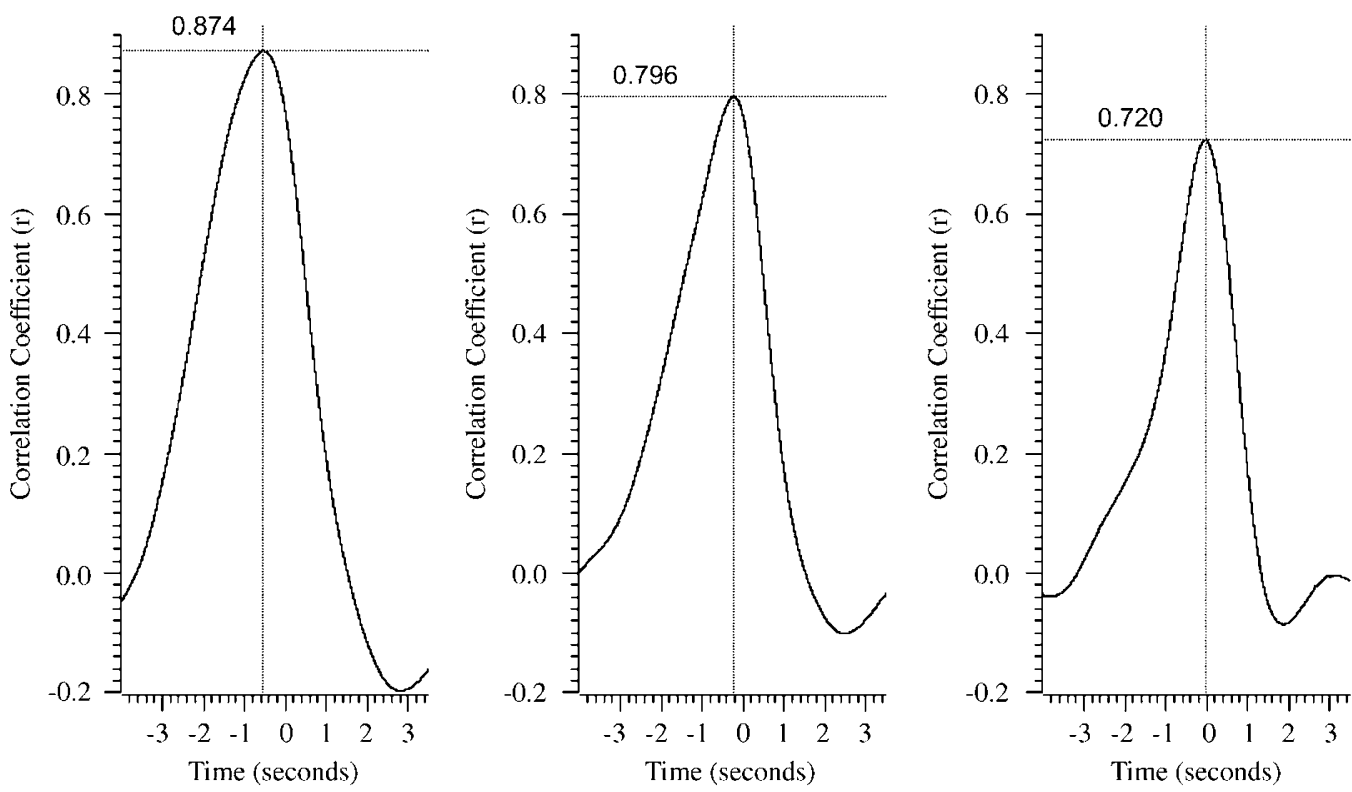

Figure 2 Coordination between eye movements and steering. Cross-correlograms of eye vs steering movements before vodka (left) after $40 \mathrm{ml}$ of vodka (center) and $100 \mathrm{ml}$ of vodka (the equivalent of two double vodkas, right), showing progressive deterioration of the relationship between eye movements and steering. $r^{2} \times 100$ is the percentage of variance in steering wheel rotation that can be attributed to covariation with horizontal eye movement; this declines from $76 \%$ (left, optimal for this subject) to 52\% (right, impaired).

every $10 \mu \mathrm{g} / 100 \mathrm{ml}$ increase in BRAC (steepest gradient, subject $\mathrm{NC}$ ) to a reduction of just $24 \mathrm{~ms}$ for every $10 \mu \mathrm{g} /$ $100 \mathrm{ml}$ increase in BRAC (subject DV).

To investigate this variation in the relationship between eye-steering time lead and BRAC in different individuals, a multiple regression was performed with subject as categorical predictor variable. This analysis showed firstly whether any chosen individual could be identified as significantly different from some other individuals in the group, and secondly whether any individuals were significantly different from the group as a whole.

Thus, firstly, choosing RJ-whose regression line gradient of $-89 \mathrm{~ms}$ per $10 \mu \mathrm{g} / 100 \mathrm{ml}$ increase in BRAC was closest to the gradient of the regression line through the group data ( $-88 \mathrm{~ms}$ per $10 \mu \mathrm{g} / 100 \mathrm{ml}$ increase in BRAC; see below), and whose data points were distributed across much of the data space - as reference subject, six other subjects were identified as significantly different from RJ $(P<0.05)$, while three were not significantly different.

Secondly, comparing each of the 10 individuals to the average relationship across all 10 subjects, using the average time lead and BRAC values before, after the first, second, and third dose of alcohol, demonstrated not only that BRAC was a significant predictor $\left(R^{2}=0.85, \mathrm{~F}=63.6, P<0.001\right)$, but also that two individuals had time lead vs BRAC relationships that were significantly different from the group as a whole $(\mathrm{CB}, \mathrm{F}=6.7, P<0.05$ and $\mathrm{RJ}, \mathrm{F}=7.4$, $P<0.05)$.

Two analyses were undertaken to obtain a picture of the effect of alcohol on time lead across the whole group of drivers (rather than focusing on individual differences). First, results from all drivers were brought together and the control drive was compared with the last test drive. Student's paired samples $t$-test confirmed that the mean time lead of eye movements over steering for this sample of drivers was significantly lower $(t=4.76, P<0.005)$ after alcohol intoxication (mean $=0.37 \mathrm{~s}, \mathrm{SD}=0.18 \mathrm{~s}$ ) than before (mean $=0.71 \mathrm{~s}, \mathrm{SD}=0.15 \mathrm{~s}$ ). To define specifically whether there was significant change in timing of coordination below the current UK limit of breath alcohol for driving, data obtained before alcohol intake and after just the first dose, after which all of the subjects remained under the legal limit, were compared. Time lead of eye movements in relation to steering was significantly reduced $(t=3.20$, $P<0.01)$ after this initial dose (mean $=0.57 \mathrm{~s}, \mathrm{SD}=0.18 \mathrm{~s}$ ).

Secondly, time-lead values from all drivers were also subject to linear regression analysis. The gradient of the fitted regression line (Figure $3 \mathrm{a}$ ) defines the rate of change of time lead with BRAC, an important group measure. A reduction of $88 \mathrm{~ms}$ for every $10 \mu \mathrm{g} / 100 \mathrm{ml}$ increase in BRAC was found. This provides several important estimates for the driving population; at half the current legal UK limit of breath alcohol for driving (ie at $17.5 \mu \mathrm{g} / 100 \mathrm{ml}$ ) the eyes will move $154 \mathrm{~ms}$ later in relation to steering, so that the time lead at zero alcohol, $710 \mathrm{~ms}$, will have reduced to $556 \mathrm{~ms}$ ( $78 \%$ of pre-alcohol value). At the legal limit ( $35 \mu \mathrm{g} /$ $100 \mathrm{ml}$ ) the eyes will move $308 \mathrm{~ms}$ later; the time lead of $710 \mathrm{~ms}$ when sober will have reduced to $402 \mathrm{~ms}$, which is just $57 \%$ of its pre-alcohol value. During this interval $(308 \mathrm{~ms})$ a car traveling at $30 \mathrm{mph}(48.3 \mathrm{~km} / \mathrm{h}, 13.4 \mathrm{~m} / \mathrm{s})$ will travel $4.13 \mathrm{~m}$.

This linear regression analysis of the group data yielded $r^{2}=0.55$ so that BRAC explains $55 \%$ of the variation in time lead of eye movements over steering across all drives by all drivers; this is lower than the $90 \%$ of variation accounted for in many individual drivers due to the differences between individuals identified within the group (see above). It nevertheless identifies a highly significant linear relationship between time lead and BRAC across all drivers in the group $(r=0.74, P<0.0001)$. 

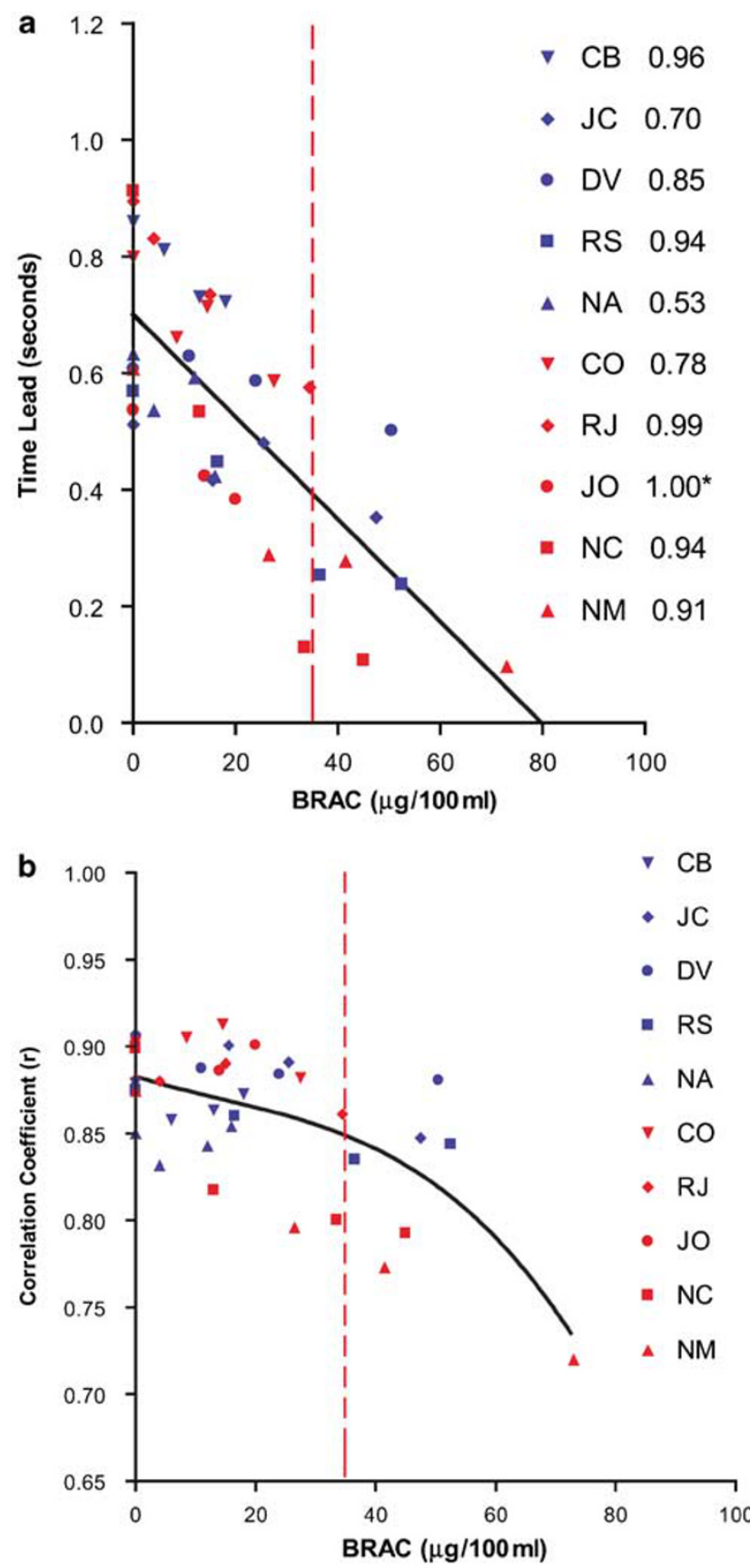

Figure 3 Effect of alcohol on the relationship between eye movements and steering. (a) Time lead of eye movements over steering plotted against BRAC. Results from individual drivers are shown by different symbols (women in red, men in blue) to permit comparison, and the regression line for the pooled data in black $(r=0.74, P<0.000 I)$. The $r^{2}$-value for each individual's regression line is given next to their initials (*indicates only three data points). (b) Correlation coefficient ( $r$-value) against BRAC. Individual drivers coded as in (a), curvilinear regression line (third order polynomial) in black. In both $\mathrm{a}$ and $\mathrm{b}$, the dashed red line at $35 \mu \mathrm{g} / \mathrm{l} 00 \mathrm{ml}$ indicates the current legal limit for alcohol when driving in the United Kingdom; the relationship between eye movements and steering is affected well below this level.

The degree of linkage (or covariation) between eye movements and steering was more robust than the timing when challenged with alcohol, suffering a gradual decline until BRAC exceeded $35 \mu \mathrm{g} / 100 \mathrm{ml}$, beyond which it decreased more sharply (Figure $3 b$ ). The relationship across the group of drivers did not therefore appear to be linear, and the data were fitted best by a third-order polynomial using curvilinear regression. Before $t$-test comparison of $r$-values obtained before alcohol intake, after the first dose and after the full dose, the Kolmogorov-Smirnov test for normality was used and confirmed that $r$-values were normally distributed at each stage (all $P>0.1$ ). Student's paired samples $t$-test confirmed that the degree of covariation between eye movements and steering for this sample of drivers was significantly lower $(t=2.44, P<0.05)$ in the final test drive after the final dose of alcohol (mean $=0.84$, $\mathrm{SD}=0.052)$ than before $($ mean $=0.88, \mathrm{SD}=0.018)$. There was also a significant reduction $(t=2.06, P<0.05)$ in the degree of covariation during the first test drive (mean $r=0.86, \mathrm{SD}=0.038$ ), for which all subjects were below the legal limit of breath alcohol for driving.

A second variable that might be expected to affect the coordination between eye movements and steering is speed of progression along the road. Figure 4a shows the effect of average speed during a drive on time lead of eye movements over steering in that drive, and Figure $4 \mathrm{~b}$ shows the effect on the degree of correlation between the two. Regression analysis confirmed that speed explained $14 \%$ of the variation in time lead across different drives, but had no effect on degree of correlation (gradient of regression line not significantly different from zero).

Since both breath alcohol and speed demonstrably affected time lead, multiple regression analysis (of nine subjects) was performed to fit a general linear model with these two explanatory variables. The resulting regression plane is shown in Figure 5, and defined by the equation

$$
\begin{aligned}
\text { Predicted time lead }= & -0.009(\text { BRAC }) \\
& -0.021 \text { (speed })+1.057 \\
& \pm 0.139
\end{aligned}
$$

This model, including both independent variables, explains $62.7 \%$ of the variance in time lead $\left(r=0.792, r^{2}=0.627\right)$. It performs better than the alternative simpler model omitting speed and using BRAC as the sole independent variable

$$
\begin{aligned}
\text { Predicted time lead }= & -0.009(\text { BRAC })+0.719 \\
& \pm 0.144
\end{aligned}
$$

which nevertheless explains $58.9 \%$ of the variance in time lead $\left(r=0.767, r^{2}=0.589\right)$. Inclusion of speed in the model (1) therefore explains an additional $3.8 \%$ of variance in time lead. In model (1) $\mathrm{F}_{(2,35)}=27.72, P<0.001$, and in model (2) $\mathrm{F}_{(1,35)}=48.72, P<0.001$. This confirms that both independent variables have a linear relationship with time lead.

In this simulated driving situation, the task of successful driving was reduced essentially to successful steering at appropriate speed along a winding road. Before alcohol, using their optimal eye movement and steering coordination, all subjects completed all drives with ease; there were no crashes. After alcohol consumption, with the disruption of coordination that entailed, a total of 19 crashes occurred. Twelve of these were major crashes, defined as excursion off-road and collision with a roadside obstacle, which halted the vehicle. There were seven minor crashes, defined as excursion off-road, with glancing collision, but with recovery to regain the carriageway. Four subjects crashed 

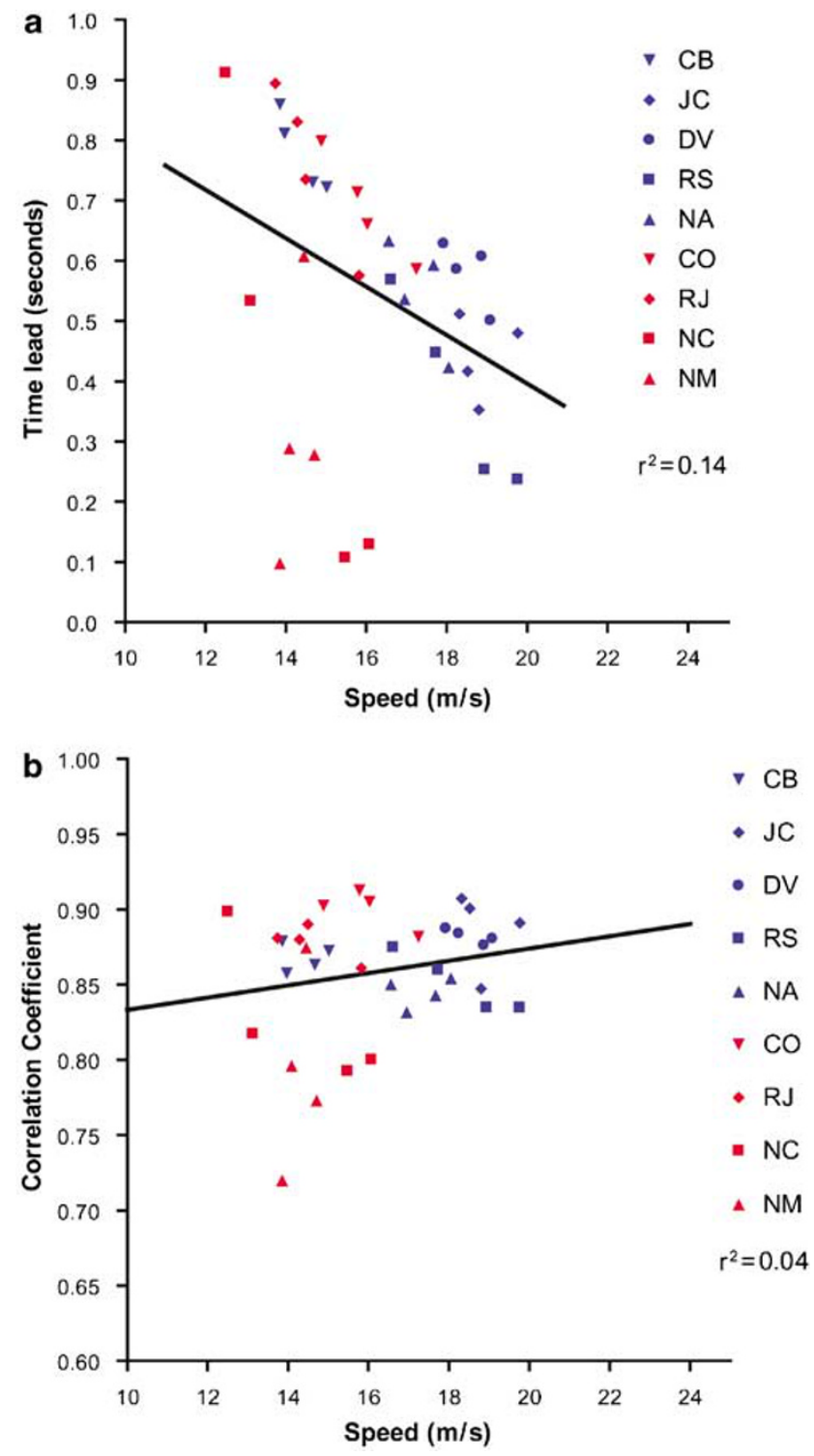

Figure 4 Effect of average speed on the relationship between eye movements and steering. (a) Time lead of eye movements over steering plotted against average driving speed. (b) Correlation coefficient ( $r$-value) against average driving speed. All conventions as in Figure 3.

(JC, CO, NM, NC), and three suffered major crashes (CO, NM, NC).

Crash incidence increased progressively with alcohol dose. Before alcohol, there were no crashes; after the first dose, there were two crashes. After the second dose there were a further 7 crashes and after the third dose another 10 crashes.

Two drivers (NM, NC) had a major crash after the first dose, while they were still below the UK legal limit. These were head-on impacts with trees at speed and would likely be fatal. A third driver (CO) had a major crash after the third dose, but was still below the legal BRAC limit. Therefore, 3 of the 10 drivers in this study suffered a likely fatal accident due to alcohol intoxication below the current legal BRAC limit $(35 \mu \mathrm{g} / 100 \mathrm{ml})$.

Did the four drivers who crashed, and the three who suffered serious crashes, respond differently to alcohol in

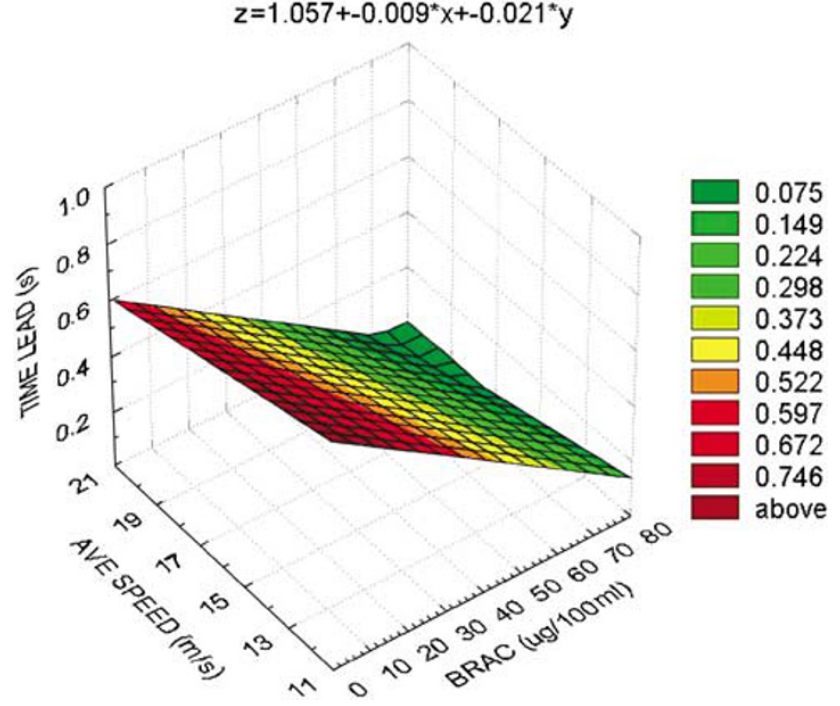

Figure 5 Multiple regression analysis with BRAC and average speed as explanatory variables. The general linear model (I) explains $62.7 \%$ of the variance in time lead of eye movements over steering.

terms of their BRAC levels and their change in eye-steering coordination compared to the six drivers who never crashed?

In terms of BRAC, two of the three with serious crashes had values higher than the legal limit after the third dose of alcohol. The third serious crash driver remained below the limit. The fourth driver who crashed also went over the limit. Therefore, of the drivers who crashed, three were among the most alcohol-intoxicated in the group of 10 individuals studied. Among the six people who did not crash, four stayed below the legal BRAC limit, and two went over. Drivers who crashed were therefore on the whole more intoxicated (higher BRAC); drivers who did not crash were on the whole less intoxicated.

In terms of the strength of effect on their eye-steering coordination, the three serious crash drivers ranked first, second, and seventh greatest change in time lead. The other crash driver ranked fourth. In terms of reduction in correlation, major crash drivers ranked first, second, and eighth greatest; the other driver who crashed ranked fifth. Therefore, two of the drivers who suffered serious crashes, who also crashed most frequently, were the two who showed the greatest change in their coordination. The other two who crashed were in the middle order of change in coordination.

The most intoxicated drivers, as measured by their BRAC, were therefore the most affected in terms of their eyesteering coordination and suffered the most frequent and most serious crashes. The crash statistics are therefore a straightforward expression of the progressively impaired ability to drive, or steer along a winding road, as alcohol intoxication progressively disrupted drivers' normal coordination between eye movements and steering.

The videotape recording of each drive showed the driver's view through the windscreen with gaze superimposed. Inspection of the videotape record of each crash was undertaken and each incident categorized according to whether the tangent point was visually acquired on 
approach, whether the car left the road on the outside or inside of the bend, and on approach to or while driving through or emerging from the bend, also whether approach speed was clearly too high so that the rear of the vehicle swung round (oversteer) with loss of traction. The results of this analysis were that only one crash occurred coming into the bend $v s 18$ during and coming out of the bend. Crashes were about three times more likely to involve going off the outside of the bend (14) than the inside (5). Eleven crashes involved failure to acquire and hold the tangent point, and seven crashes involved too high speed of approach, with loss of traction and swing of the rear of the car. Therefore, a crash hardly ever involved early steering in the direction of the bend. Typically, a crash involved going off the outside of the bend as the driver steered round the bend or emerged from it, with contributing factors being too high speed of approach and failure to fixate the tangent point.

\section{DISCUSSION}

The two main findings of this study are firstly that a driver's optimal relationship between eye and steering movements deteriorates during drink driving below the legal limit for alcohol in the United Kingdom (BRAC of $35 \mu \mathrm{g} / 100 \mathrm{ml}$ ). Measured across a group of 10 drivers, the lowest dose of alcohol we used $(1.8 \mathrm{U})$ significantly affected this essential aspect of driving. Secondly, we have found that this impaired coordination is accompanied by impaired driving that in 4/10 individuals resulted in crashes that in the real world would cause serious injury or death; three of these drivers were below the current legal breath alcohol limit when they crashed. These findings are clear evidence that the current UK limit should at least be reduced to a BRAC of $22 \mu \mathrm{g} / 100 \mathrm{ml}$, as in the majority of European states. A significant progressive relationship between increasing BRAC and increasingly impaired eye-steering coordination (later eye movements when approaching bends) was identified in $7 / 10$ drivers.

The effect of alcohol on eye-steering coordination varied between individuals. Any chosen individual could be identified as significantly different from some others within the group, and two individuals were significantly different from the group as a whole. The most intoxicated drivers, as measured by their BRAC, were the most affected in terms of their eye-steering coordination and suffered the most frequent and most serious crashes. The crash statistics are therefore a straightforward expression of the progressively impaired ability to drive, or steer along a winding road, as alcohol intoxication progressively disrupted drivers' normal coordination between eye movements and steering.

These parallel changes in eye-steering coordination and ability to steer around bends suggest a neural mechanism for impaired driving due to alcohol. When driving normally (optimally), the $0.7 \mathrm{~s}$ time lead of eye movements over steering reflects the fact that the parts of the brain that control the eyes are working ahead of the parts of the brain that control the hands on the wheel. The oculomotor controller can therefore assist in controlling steering (Marple-Horvat et al, 2005; Hollands and Marple-Horvat, 1996; Miall and Reckess, 2002). The neural mechanism might involve the results of calculations made to move the eyes being passed across and fed into the neural controller for steering (Crowdy et al, 2000; Marple-Horvat et al, 2005; Miall and Reckess, 2002), probably within the cerebellum which is thought to contain linked neural controllers for the eyes, head and limbs essential for visual guidance of coordinated movements (Miall and Reckess, 2002; Miall et al, 2000, 2001). This help needs to arrive in time, and at the appropriate time, to steer around the corner, so that the eyes move with an optimal time lead (Miall and Reckess, 2002) over steering.

Optimal coordination is disrupted by alcohol intoxication. During drink driving, the time lead of eye movements over steering reduces because the eyes move later in relation to upcoming bends. The alternative possibility, that reduced time lead is due to earlier steering in relation to an approaching bend, can be ruled out for the following reasons. First, during successful (but intoxicated) negotiation of the winding route, the reduced interval cannot be a result of earlier steering since timing of successful steering of necessity remains tightly linked to the road-early steering would guide the vehicle off the carriageway in the direction of, but before, an approaching bend. Secondly, we found no evidence of early steering during unsuccessful negotiation of the route. The results of crash analysis were that only one crash occurred coming into the bend, $v s 18$ during and coming out of the bend. Crashes were also three times more likely to involve going off the outside of the bend than the inside. Therefore, a crash hardly ever involved early steering in the direction of the bend. Contributory factors that were identified were failure to acquire and hold the tangent point (11 incidents) and too high speed of approach ( 7 incidents).

With reduced time lead, help from the oculomotor controller to the steering controller does not arrive at the appropriate time and, deprived of this assistance, steering performance suffers, sometimes resulting in crashes. As in other situations, bad or late eye movements ill-coordinated with other actions explain bad performance (van Donkelaar and Lee, 1994; Crowdy et al, 2000; Marple-Horvat et al, 2005; Miall and Reckess, 2002; Crowdy and Marple-Horvat, 2004; Wilson et al, 2007).

An implication of this study is that there should be a significant number of accidents, involving drivers both below and above the legal limit for alcohol, in which simple failure to steer around a bend in the road (more often going off the outside than the inside of the bend), without other complicating factors, was the apparent cause of the accident. It will be important to verify this either by inspecting existing accident records, or if such information has not been logged, by changing the routine methods of recording to include such information in future. There are good grounds for believing that the impaired coordination identified in the simulator, and the crash incidents observed, are indeed similar to the change in driving performance and crash incidents that occur in actual driving. Thus, comparison of driving in this simulator (Marple-Horvat et al, 2005; Wilson et al, 2007) with actual driving on the road (Chattington et al, 2007) has already identified that these are highly similar in terms of the eyesteering coordination seen in each case. The essentials are the same. There is a tight linkage between eye movements and steering, the relationship is highly linear and stationary, 
the eyes lead steering, and any disruption of the normal optimal eye-steering relationship impairs driving performance. This is reassuring evidence for the realistic nature and validity of the simulation (which avoided use of only very short drive times, over-simplified routes, inadequate graphical representation of a recognizable road and so on).

This study has defined how the optimal coordination between eye movements and steering when driving is affected by alcohol. This knowledge can be applied to produce an automatic in-car detection system, an in-car eye movement and steering analyzer, which measures eyesteering coordination by computing cross-correlograms for successive periods of driving. For example, the crosscorrelogram, timing and $r$-values for the last $3 \mathrm{~min}$ of a journey to a destination where alcohol was consumed could be compared to the first $3 \mathrm{~min}$ of the following journey when the driver might still have significant levels of blood and breath alcohol. Such comparison would identify any difference between the pre-alcohol, optimal and postalcohol, impaired eye movement-to-steering relationship and the device could warn the driver that their coordination had been disrupted, with an effect on driving performance that meant she/he was no longer safe or fit to drive. This device is currently being road-tested, and could be incorporated into vehicle safety systems without difficulty. A major advantage of such a device is that any factor that seriously affects the eye movement-to-steering relationship could be detected, including not only alcohol, but also prescription or illegal drugs, distraction, and fatigue.

\section{DISCLOSURE/CONFLICT OF INTEREST}

A United States patent (No. 6974326) was granted on 13 December 2005 to DE Marple-Horvat and the University of Bristol, for a method and apparatus for determining whether a person's ability to drive a motor vehicle has become impaired. This COrrelation-based DRIVing Analyzer (CO-DRIVA) is a form of automatic driving impairment detector. DE Marple-Horvat has received no compensation for professional services from any source in any of the previous three years. The University of Bristol is seeking partners to develop the patented device, and if successful DE Marple-Horvat anticipates receiving some compensation in the future. None of the other authors has any conflict of interest whatsoever.

\section{REFERENCES}

Beauchamp KG (1973). Signal Processing Using Analog and Digital Techniques. George Allen and Unwin Ltd: London.

Calhoun VD, Pekar JJ, Pearlson GD (2004). Alcohol intoxication effects on simulated driving: exploring alcohol-dose effects on brain activation using functional MRI. Neuropsychopharmacology 29: 2097-2107.

Carvalho KN, Pearlson GD, Astur RS, Calhoun VD (2006). Simulated driving and brain imaging: combining behavior, brain activity, and virtual reality. CNS Spectr 11: 52-62.

Chattington M, Wilson M, Ashford D, Marple-Horvat DE (2007). Eye-steering coordination in natural driving. Exp Brain Res (26 January 2007; E-pub ahead of print).

Chu NS (1983). Effects of ethanol on rat cerebellar Purkinje cells. Int J Neurosci 21: 265-277.
Crowdy KA, Hollands MA, Ferguson IT, Marple-Horvat DE (2000). Evidence for interactive locomotor and oculomotor deficits in cerebellar patients during visually guided stepping. Exp Brain Res 135: 437-454.

Crowdy KA, Kaur-Mann D, Cooper HL, Mansfield AG, Offord JL, Marple-Horvat DE (2002). Rehearsal by eye movement improves visuomotor performance in cerebellar patients. Exp Brain Res 146: 244-247.

Crowdy KA, Marple-Horvat DE (2004). Alcohol affects eye movements essential for visually guided stepping. Alcohol Clin Exp Res 28: 402-407.

Diener HC, Dichgans J, Bacher M, Hulser J, Liebich H (1983). Mechanisms of postural ataxia after intake of alcohol. $Z$ Rechtsmed 90: 159-165.

van Donkelaar P, Lee RG (1994). Interactions between the eye and hand motor systems: disruptions due to cerebellar dysfunction. J Neurophysiol 72: 1674-1685.

Evans L (2004). Traffic Safety. Science Serving Society: Michigan, USA.

Furneaux S, Land MF (1999). The effects of skill on the eyehand span during musical sight-reading. Proc R Soc Lond B 266: 2435-2440.

Harper C (1998). The neuropathology of alcohol-specific brain damage, or does alcohol damage the brain? J Neuropathol 57: 101-110.

Haubek A, Lee K (1979). Computed tomography in alcoholic cerebellar atrophy. Neuroradiology 18: 77-79.

Herman R, Herman R, Maulucci R (1981). Visually triggered eye-arm movements in man. Exp Brain Res 42: 392-398.

Hollands MA, Marple-Horvat DE (1996). Visually guided stepping under conditions of step cycle-related denial of visual information. Exp Brain Res 109: 343-356.

Hollands MA, Marple-Horvat DE (2001). Coordination of eye and leg movements during visually guided stepping. J Motor Behaviour 33: 205-216.

Hollands MA, Marple-Horvat DE, Henkes S, Rowan AK (1995). Human eye movements during visually guided stepping. J Motor Behav 27: 155-163.

Holmes G (1939). The cerebellum of man. Brain 62: 1-30.

Johnson-Greene D, Adams KM, Gilman S, Kluin KJ, Junck L, Martorello S et al (1997). Impaired upper limb coordination in alcoholic cerebellar degeneration. Arch Neurol 54: 436-439.

Land MF, Furneaux S (1997). The knowledge base of the oculomotor system. Phil Trans $R$ Soc Lond B 352: 1231-1239.

Land MF, Hayhoe M (2001). In what ways do eye movements contribute to everyday activities? Vision Res 41: 3559-3565.

Land MF, Lee DN (1994). Where we look when we steer. Nature 369: 742-744.

Liguori A, D'Agostino Jr RB, Dworkin SI, Edwards D, Robinson JH (1999). Alcohol effects on mood, equilibrium, and simulated driving. Alcohol Clin Exp Res 23: 815-821.

Lynn PA (1982). An Introduction to the Analysis and Processing of Signals, 2nd edn. Macmillan: London.

Marple-Horvat DE, Chattington M, Anglesea M, Ashford DG, Wilson M, Keil D (2005). Prevention of coordinated eye movements and steering impairs driving performance. Exp Brain Res 163: 411-420.

Marple-Horvat DE, Crowdy KA (2005). Direct visualisation of gaze and hypometric saccades in cerebellar patients during visually guided stepping. Gait Posture 21: 39-47.

Miall RC (1998). The cerebellum, predictive control and motor coordination. Novartis Found Symp 218: 272-284.

Miall RC, Imamizu H, Miyauchi S (2000). Activation of the cerebellum in co-ordinated eye and hand tracking movements: an fMRI study. Exp Brain Res 135: 22-33.

Miall RC, Reckess GZ (2002). The cerebellum and the timing of coordinated eye and hand tracking. Brain Cogn 48: 212-226. 
Miall RC, Reckess GZ, Imamizu H (2001). The cerebellum coordinates eye and hand tracking movements. Nat Neurosci 4: 638-644.

Moskowitz H, Burns MM, Williams AF (1985). Skills performance at low blood alcohol levels. J Stud Alcohol 46: 482-485.

Nieschalk M, Ortmann C, West A, Schmal F, Stoll W, Fechner G (1999). Effects of alcohol on body-sway patterns in human subjects. Int J Legal Med 112: 253-260.

Ogden EJ, Moskowitz H (2004). Effects of alcohol and other drugs on driver performance. Traffic Inj Prev 5: 185-198.

Perez-Reyes M, Hicks RE, Bumberry J, Jeffcoat AR, Cook CE (1988). Interaction between marihuana and ethanol: effects on psychomotor performance. Alcohol Clin Exp Res 12: 268-276.

Ramaekers JG, Robbe HW, O'Hanlon JF (2000). Marijuana, alcohol and actual driving performance. Hum Psychopharmacol 15: $551-558$

Sloboda JA (1974). The eye-hand span: an approach to the study of sight-reading. Psychol Music 2: 4-10.
Sullivan EV, Deshmukh A, Desmond JE, Lim KO, Pfefferbaum A (2000). Cerebellar volume decline in normal aging, alcoholism, and Korsakoff's syndrome: relation to ataxia. Neuropsychology 14: 341-352.

Torvik A, Torp S (1986). The prevalence of alcoholic cerebellar atrophy. A morphometric and histological study of autopsy material. J Neurol Sci 75: 43-51.

Weiler JM, Bloomfield JR, Woodworth GG, Grant AR, Layton TA, Brown TL et al (2000). Effects of fexofenadine, diphenhydramine, and alcohol on driving performance. A randomized, placebo-controlled trial in the Iowa driving simulator. Ann Intern Med 132: 354-363.

Wilkie RM, Wann JP (2003). Eye-movements aid the control of locomotion. J Vis 3: 677-684.

Wilson M, Stephenson S, Chattington M, Marple-Horvat DE (2007). Eye movements coordinated with steering benefit performance even when vision is denied. Exp Brain Res 176: 397-412. 